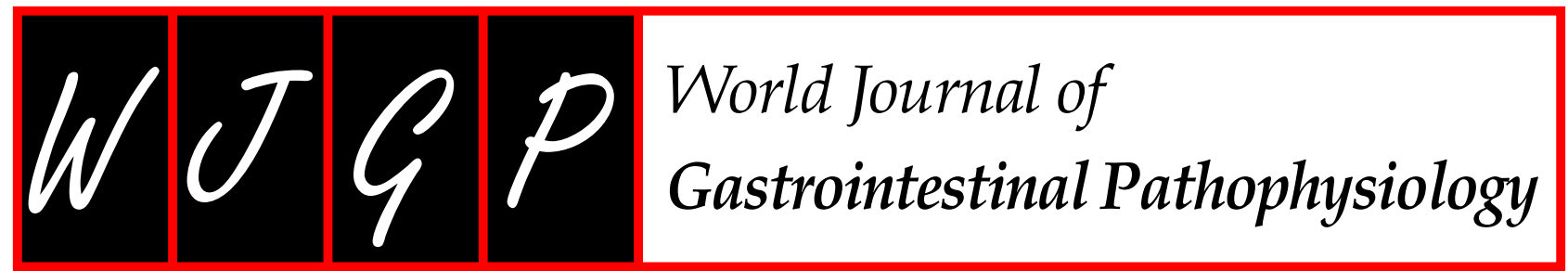

Online Submissions: http:/ / www.wjgnet.com/2150-5330office wjgp@wjgnet.com

World J Gastrointest Pathophysiol 2010 April 15; 1(1): 1-2 doi:10.4291/wjgp.v1.i1.1 (C) 2010 Baishideng. All rights reserved.

\title{
What is the purpose of launching World Journal of Gastrointestinal Pathophysiology?
}

\author{
Lian-Sheng Ma
}

Lian-Sheng Ma, Beijing Baishideng BioMed Scientific Co., Ltd., Beijing 100025, China

Author contributions: Ma LS solely contributed to this paper. Correspondence to: Lian-Sheng Ma, President and Editorin-Chief, Beijing Baishideng BioMed Scientific Co., Ltd., Room 903, Building D, Ocean International Center, No. 62 Dongsihuan Zhonglu, Chaoyang District, Beijing 100025,

China.1.s.ma@wjgnet.com

Telephone: +86-10-59080036 Fax: +86-10-85381893

Received: September 3, 2009 Revised: September 10, 2009

Accepted: September 17, 2009

Published online: April 15, 2010

\begin{abstract}
The first issue of World Journal of Gastrointestinal Pathophysiology (WJGP), whose preparatory work was initiated in June, 2009, is published on April 15, 2010. The WJGP Editorial Board has now been established and consists of 154 distinguished experts from 27 countries. Our purpose of launching WJGP is to publish peer-reviewed, high-quality articles via an open-access online publishing model, thereby acting as a platform for communication between peers and the wider public, and maximizing the benefits to editorial board members, authors and readers.
\end{abstract}

(C) 2010 Baishideng. All rights reserved.

Key words: Maximization of personal benefits; Editorial board members; Authors; Readers; Employees; World Journal of Gastrointestinal Pathophysiology

Ma LS. What is the purpose of launching World Journal of Gastrointestinal Pathophysiology? World J Gastrointest Pathophysiol 2010; 1(1): 1-2 Available from: URL: http://www. wjgnet.com/2150-5330/full/v1/i1/1.htm DOI: http://dx.doi. org/10.4291/wjgp.v1.i1.1

\section{INTRODUCTION}

I am very pleased to announce that the first issue of World Journal of Gastrointestinal Pathophysiology (World J Gastrointest Pathophysiol, WJGP, online ISSN 2150-5330, DOI: 10.4291) is published on April 15, 2010. The WJGP Editorial Board has now been established and consists of 154 distinguished experts from 27 countries.

The role of academic journals is to exhibit the scientific levels of a country, a university, a center, a department, and even a scientist, and build an important bridge for communication between scientists and the public. As we all know, the significance of the publication of scientific articles lies not only in disseminating and communicating innovative scientific achievements and academic views, as well as promoting the application of scientific achievements, but also in formally recognizing the "priority" and "copyright" of innovative achievements published, as well as evaluating research performance and academic levels. To realize these desired attributes of a journal and create a well-recognized journal, the following four types of personal benefits should be maximized.

\section{MAXIMIZATION OF PERSONAL BENEFITS}

The maximization of personal benefits refers to the pursuit of the maximum personal benefits in a wellconsidered optimal manner without violation of the laws, ethical rules and the benefits of others.

\section{Maximization of the benefits of editorial board members} The primary task of editorial board members is to give a peer review of an unpublished scientific article via online office system to evaluate its innovativeness, scientific and practical values and determine whether it should be published or not. During peer review, editorial board members can also obtain cutting-edge information in that field at first hand. As leaders in their field, they 
have priority to be invited to write articles and publish commentary articles. We will put peer reviewers' names and affiliations along with the article they reviewed in the journal to acknowledge their contribution.

\section{Maximization of the benefits of authors}

Since WJGP is an open-access journal, readers around the world can immediately download and read, free of charge, high-quality, peer-reviewed articles from WJGP official website, thereby realizing the goals and significance of the communication between authors and peers as well as public reading.

\section{Maximization of the benefits of readers}

Readers can read or use, free of charge, high-quality peer-reviewed articles without any limits, and cite the arguments, viewpoints, concepts, theories, methods, results, conclusion or facts and data of pertinent literature so as to validate the innovativeness, scientific and practical values of their own research achievements, thus ensuring that their articles have novel arguments or viewpoints, solid evidence and correct conclusion ${ }^{[1]}$.

\section{Maximization of the benefits of employees}

It is an iron law that a first-class journal is unable to exist without first-class editors, and only first-class editors can create a first-class academic journal ${ }^{[2,3]}$. We insist on strengthening our team cultivation and construction so that every employee, in an open, fair and transparent environment, could contribute their wisdom to edit and publish high-quality articles, thereby realizing the maximization of the personal benefits of editorial board members, authors and readers, and yielding the greatest social and economic benefits.

\section{CONTENTS OF PEER REVIEW}

In order to guarantee the quality of articles published in the journal, WJGP usually invites three experts to comment on the submitted papers. The contents of peer review include: (1) whether the contents of the manuscript are of great importance and novelty; (2) whether the experiment is complete and described clearly; (3) whether the discussion and conclusion are justified; (4) whether the citations of references are necessary and reasonable; and (5) whether the presentation and use of tables and figures are correct and complete.

\section{SCOPE}

The major task of WJGP is to report rapidly the most recent results in basic and clinical research on gastroin- testinal pathophysiology, including all aspects of normal or abnormal function of the gastrointestinal tract, hepatobiliary system, and pancreas. WJGP specifically covers growth and development, digestion, secretion, absorption, metabolism and motility relative to the gastrointestinal organs, as well as immune and inflammatory processes, and neural, endocrine and circulatory control mechanisms that affect these organs. This journal will also report new methods and techniques in gastrointestinal pathophysiological research.

\section{COLUMNS}

The columns in the issues of WJGP will include: (1) Editorial: To introduce and comment on major advances and developments in the field; (2) Frontier: To review representative achievements, comment on the state of current research, and propose directions for future research; (3) Topic Highlight: This column consists of three formats, including (A) 10 invited review articles on a hot topic, (B) a commentary on common issues of this hot topic, and (C) a commentary on the 10 individual articles; (4) Observation: To update the development of old and new questions, highlight unsolved problems, and provide strategies on how to solve the questions; (5) Guidelines for Basic Research: To provide Guidelines for basic research; (6) Guidelines for Clinical Practice: To provide guidelines for clinical diagnosis and treatment; (7) Review: To review systemically progress and unresolved problems in the field, comment on the state of current research, and make suggestions for future work; (8) Original Articles: To report innovative and original findings in gastrointestinal pathophysiology; (9) Brief Articles: To briefly report the novel and innovative findings in gastrointestinal pathophysiology; (10) Case Report: To report a rare or typical case; (11) Letters to the Editor: To discuss and make reply to the contributions published in WJGP, or to introduce and comment on a controversial issue of general interest; (12) Book Reviews: To introduce and comment on quality monographs of gastrointestinal pathophysiology; and (13) Guidelines: To introduce Consensuses and Guidelines reached by international and national academic authorities worldwide on basic research and clinical practice in gastrointestinal pathophysiology.

\section{REFERENCES}

1 Zhu DM. Zhu DM: What is the purpose of literature citation? Science Times, 2009-07-17 Available from: URL: http://www.sciencenet.cn/htmlnews/2009/7/221552.shtm

2 Li ZX. See the "sallying forth" of Chinese scientific and technical journals from the innovative business model of WJG. Zhongguo Keji Qikan Yanjiu 2008; 19: 667-671

3 Xiao H. First-class publications can not do without firstclass editorial talents. Keji Yu Chuban 2008; (3): 192 